\title{
ARCHIVO
}

\section{La Danza de Carlomagno}

A Senén Bernardo

En la comarca leonesa de La Cabrera sigue todavía muy vivo el recuerdo de sus danzas de paloteo y de sus representaciones teatrales, con motivo de la festividad del Corpus Christi. En Corporales (Cabrera Alta) tenemos la «Danza del rey Nabucodonosor», con un texto basado en el libro sagrado del profeta Daniel ${ }^{1}$, y en La Baña (Cabrerta Baja) la «Danza de Carlomagno», cuya fuente más cercana se encuentra en los romances que sobre Carlomagno escribiera Juan José López ${ }^{2}$, autor del siglo XviII; romances publicados en pliegos de cordel durante los dos últimos siglos, y que también recoge Agustín Durán en el Romancero General ${ }^{3}$. Estos versos romanceados de Juan José López se basan en la Historia de Carlo Magno de Nicolás de Piamonte (Sevilla, 1525), obra que también inspiró a Calderón de la Barca La puente de Mantible 4 .

La «Danza de Carlomagno» se representó en La Baña por última vez en 1948, después de muchos años que ya no se hacía. En el pueblo vivían aún gentes que la recordaban, y de esa época data el manuscrito que tiene uno de sus vecinos. Manuscrito que hemos podido transcribir y completar

1 Se ha publicado parte del texto, aquéllo que recordaban en el pueblo, en Tierras de León, n. 64 (1986), pp. $61-64$ (artículo de Maximino Descosido Fuertes).

2 Más adelante damos cuenta de uno de los pliegos de este autor. Puede consultarse también F. AgUILAR PIÑAl, Romancero popular del siglo XVIII (Madrid: C.S.I.C., 1972), ns. 765-766, así como los ns. 12 al 27.

3 Cf. B.A.E., tomo XVI, vol. II, pp. 229-245. ( «Romances vulgares caballerescos: Romances de Carlo-Magno y los Doce Pares de Francia que contienen el desafío de Oliveros y Fierabrás, los amores de Floripes y Guy de Borgoña, con otras muchas aventuras, amores y guerras. Asimismo se refiere a la batalla de Roncesvalles, la muerte de Roldán y de otros Pares de Francia, todo según el libro vulgar de Carlo-Magno y la Crónica del Arzobispo Turpín»).

4 Cf. Julio Caro Baroja, Ensayo sobre la Literatura de cordel (Madrid: Edics. de la Revista de Occidente, 1969), pp. 77 y 320-321. (Hay edición del Círculo de Lectores, 1988). La obra de Nicolás de Piamonte es una traducción derivada del Speculum Historiale de Beauvais, del poema francés Fierabrás y de la Crónica de Turpín. 
con otros informantes de la localidad, los cuales con prodigiosa memoria nos recitaron y cantaron muchas de sus partes s.

Los versos del texto - que damos a continuación- se cantaban todos con la misma melodía; una melodía muy simple, que nos recordó los cantares de ciego. Y en la representación se intercalaban los paloteados, acompañados con los sones de la gaita de fuelle.

El día del Corpus tenía lugar la procesión con los danzantes y dos representaciones de la obra: una, por la mañana, para los pastores que marchaban al monte con el ganado y, la otra, por la tarde para todo el pueblo.

Informantes de La Baña (que participaron en la representación del año 1948)

- Lázaro Fernández, tiene 70 años, hizo de Oliveros.

- José Fernández, tiene 70 años, hizo de Guy de Borgoña.

- Plácido Vega, tiene 73 años, hizo de rey moro.

- Celia Martínez, tiene 57 años, hizo de Floripes.

- Recuerdan también muchos pasajes de la danza: Manuel Maestre, de 57 años, y Aurelio Bayo, de 56 años, que actualmente vive en Madrid. Éstos la vieron representar pero no trabajaron en ella.

Personajes (son 15, incluidos el gracioso o remixiaco y el gaitero)

\section{CRISTIANOS}

- Rey cristiano (Carlomagno)

- Segundo cristiano (Oliveros)

- Tercer cristiano (Roldán)

- Cuarto cristiano (interpreta el personaje de Guarín, de Ricarte de Normandía y de Ogier de Dinamarca)

- Quinto cristiano (Guy de Borgoña y Apóstol Santiago)

- Sexto cristiano (Galalón y Duque de Naimes)

MOROS

- Rey moro (Balán)

- Segundo moro (Fierabrás)

S El manuscrito nos fue descubierto por Senén Bernardo, a quien agradecemos su valiosísima colaboración. Él nos puso en contacto con los informantes, nos acompañó por tierras de Cabrera, nos acogió en su casa de Robledo de Losada, y él hizo las fotos que ilustran este artículo. 
- Tercer moro

- Cuarto moro

- Quinto moro

- Dama (Floripes, hija de Balán y hermana de Fierabrás)

La indumentaria de los personajes consiste en calzón blanco de lino, media de lana blanca con dibujos y botas de cuero. Llevan camisa blanca y una banda ancha de lino con bordados polícromos a crucetilla. Una corbata, también de lino, que recuerda la estola sacerdotal, bordada en colores con un motivo religioso. A la cabeza, sombrero adornado de cintas o colonias y plumas de pavo real. La única diferencia que existe entre el traje de moros y cristianos es la forma en que colocan la banda de lino: los cristianos la cruzan sobre el hombro derecho y, los moros, sobre el izquierdo.

El gracioso o remixiaco ${ }^{6}$ viste de encarnado y lleva un palo en la mano para fustigar a las personas y abrir el corro durante la representación. La dama se viste con las mejores prendas festivas del pueblo y lleva una especie de toca blanca. Este personaje antiguamente lo representaba un muchacho, pero ya la última vez (en 1948) fue una mujer joven la que hizo de Floripes, y ella ha sido una de nuestros informantes.

\section{FUENTE BASE}

Historia de Carlo-Magno y de los Doce Pares de Francia. En ella se refieren las grandes proezas $y$ hazañas de estos muy nobles y esforzados caballeros. Madrid, Despacho: Librería y Casa Editorial Hernando (S.A.), Calle del Arenal, núm. 11. Son cuatro pliegos, con ocho partes; en la estrofa final aparece el nombre del autor, Juan José López:

Primera parte. Se da cuenta del muy sangriento combate que tuvo el valeroso Oliveros con el esforzado Fierabrás de Alejandría.

Segunda parte. Prosigue el tenaz combate entre el valeroso Oliveros y su contrario el esforzado Fierabrás. Conversión de Fierabrás al cristianismo.

Tercera parte. La princesa Floripes presta su apoyo a los ilustres prisioneros. Embajada por una y otra parte para el canje de prisioneros.

6 Relacionado con remixiar (<rĕmiscere) 'remover, mezclar revolviendo', cf. C. Casado Lobato, El habla de la Cabrera alta. Contribución al estudio del dialecto leonés (Madrid: C.S.I.C., 1948), pp. 59 y 114. 
Cuarta parte. Amores de la princesa mora con Guy de Borgoña. Manda el Almirante prender a los embajadores. Insurrección de los prisioneros de la torre.

Quinta parte. Sálvase Guy de Borgoña de un grande apuro. Combate en el puente de Mantible. Paso del ejército cristiano por el puente.

Sexta parte. Combate parcial de Carlo-Magno. Apresamiento y muerte del Almirante. Regresa Carlo-Magno a Francia.

Séptima parte. Aparición del apóstol Santiago. Conquista de Galicia. Combate de Roldán con Ferraguz. Hallazgo del cuerpo de Santiago.

Octava y última parte. Horrible traición en Roncesvalles. Muerte de los doce Pares. Sentimiento de Carlo-Magno. Derrota de los moros. Conclusión ?.

7 Ejemplar en la Biblioteca del Instituto de Filología del C.S.I.C., sección de Etnografía, signatura $2 / 1$. 


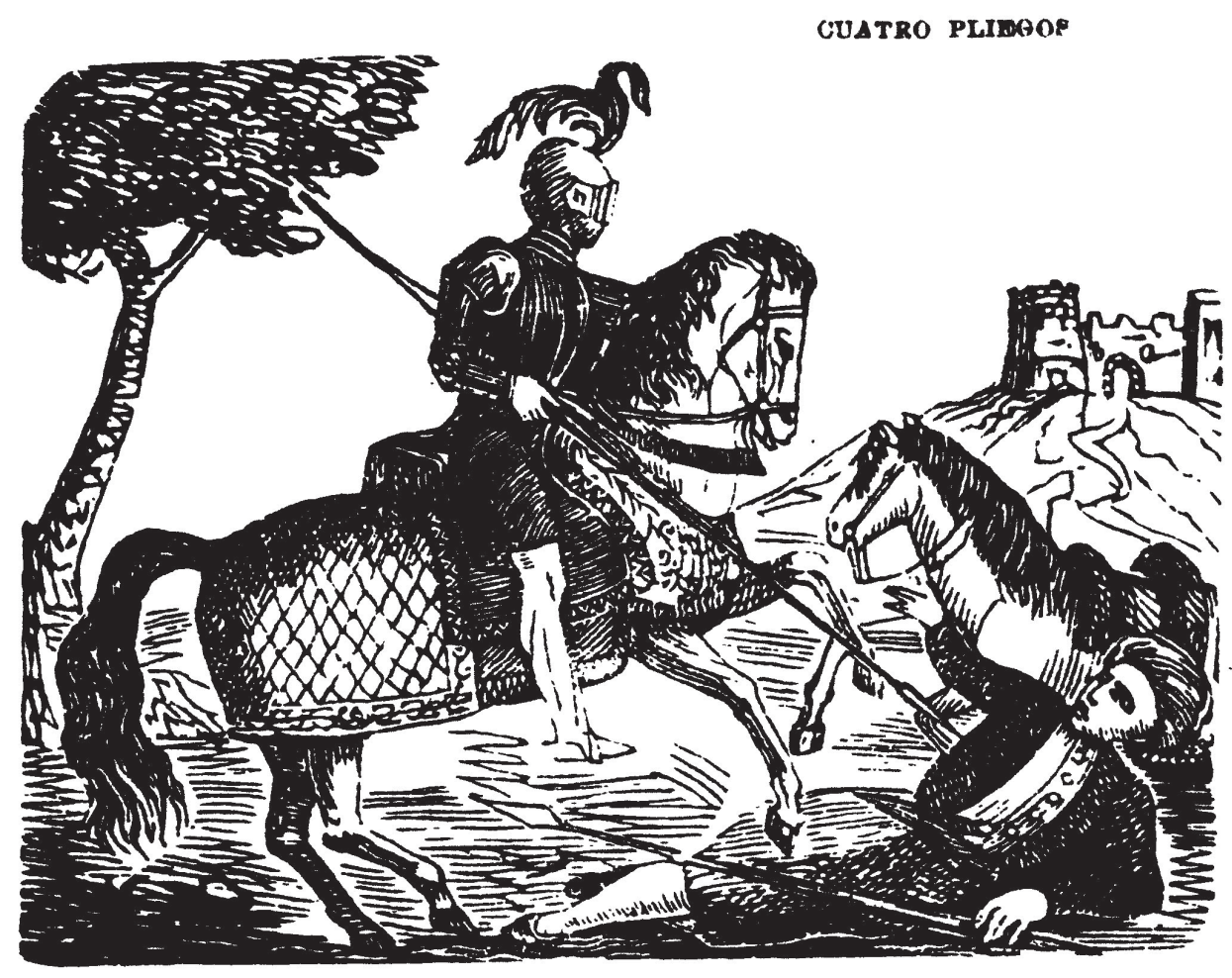

IISTORIA

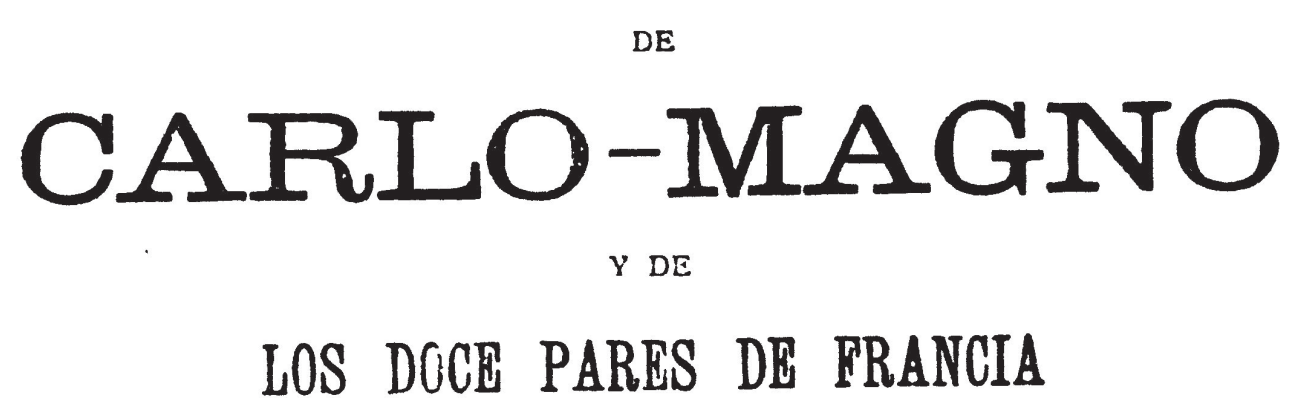

En ella se refieren las grandes proezas y hazafias de estos muy nobles $y$ esforzados caballeros.

\section{MADRID}

MADRID
Despacho: Libreria y Casa Editorial Hernando (Sallo del Arena, núm. 11.
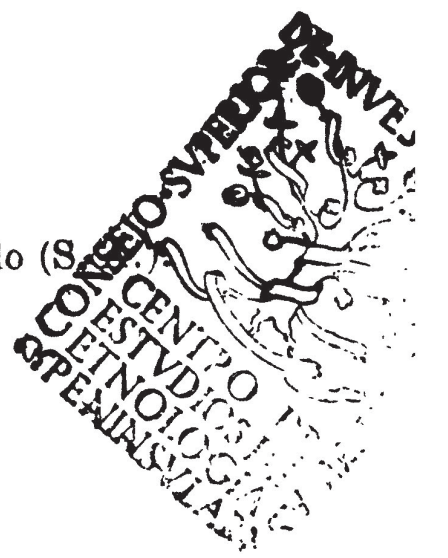

Fig. 1.-Pliego de cordel con el texto romanceado de Juan José López. 
T E X T O

D E L A

D A N Z A D E CARLOMAG N O

\title{
ANUNCIO: Se anuncia la guerra de Fierabrás y Oliveros
}

\author{
[1." parte] Suenen cajas y clarines \\ y sonoros instrumentos, \\ en acordes consonancias \\ por los espacios del tiempo... \\ la más reñida batalla \\ y los más recios encuentros \\ que ha habido entre espada y lanza, \\ mano a mano y cuerpo a cuerpo. \\ Has saber como en Turquía, \\ en aquellos pasados tiempos, \\ el almirante Balán \\ señor de todo su reino ${ }^{8}$ \\ el cual crió un hijo \\ agigantado en su cuerpo, \\ mide quice pies de largo \\ y otros tantos tien de grueso. \\ Este, puesto en campaña, \\ era una torre de huesos. \\ REY MORO (BALÁN) \\ ¡Ea! pues, mis caballeros, \\ fuertes nobles y bizarros, \\ a la guerra buenos mozos, \\ siempre leales vasallos; \\ pues hais de saber que ya \\ el emperador Carlomagno \\ ha entrado en Jerusalén \\ y todo lo ha conquistado. \\ Desde allí pasó a Roma \\ con su muy lucido bando,
}

8 El texto base de Juan José López continúa: «tenía un hijo disforme, / agigantado en su cuerpo...». 
y dicen también vendrá
por las reliquias tan bellas
que mi hijo Fierabrás
venció a hombres de pelea.
Mucho me alegraría yo
que uno de mis caballeros
me trajera aquí a Roldán
y a Oliveros prisioneros.

Estos son los dos varones

que a mis tropas ponen miedo.

Estos son aquellos reyes

que rigen aquel ejército.

(Le dice el rey moro a su bijo Fierabrás)

Partid vos, hijo mío,

y ponedles sangrienta guerra,

que en vuestra campaña irán

ciento cincuenta mil hombres,

todos hombres de pelea.

Mientras no conquistéis Francia,

no volveréis a esta tierra.

2. MORO (FIERABRÁS)

Eso queda de mi empeño, yo bien quisiera ser dueño de todo el reino de Francia.

Pues dadme licencia

y yo iré al campo, donde tiene su real puesto, y los llamaré a campaña

por ver si puede mi esfuerzo uno a uno, dos a dos, daré fin a todos ellos.

REY MORO (BALÁN)

Bien sabes, hijo animoso, * que estos doce caballeros

* Así comienza el manuscrito de La Baña; todo lo anterior no está en este ms., pero lo recordaban algunos informantes. 
que vienen con Carlomagno

son hombres de mucho arresto.

Me han matado cien mil hombres,

y mis mejores guerreros.

¡Por el profeta de Alá 9

les hago hoy juramento

que he de tomar la demanda

y me he de vengar de ellos!

2. ${ }^{\circ}$ MORO (FIERABRÁS)

Padre mío muy amado

a mí nada me ha costado

de obedecer vuestro mandado.

A (sic) todos los doce pares

vengan presos a mi lado

y al mismo rey, si lo veo, de mí ha de ser castigado.

Altos, nobles caballeros, sólo con vuestra arrogancia

yo bien quisiera ser

dueño del reino de Francia.

Carlomagno, ya has perdido

todo tu honor y tu fama

que antes habías ganado,

mas por Mahoma te juro

que he de pregonar a voces

tu cobardía por el mundo.

Carlomagno, Carlomagno, pues que tan nombrado eres, ¿Cómo a salir no te atreves

a pelear con Fierabrás?

$A$ un rey que si le das guerra, que está al tanto de los moros, y ahora uno que os llama

estáis enjaulados todos.

Habéis perdido las fuerzas

en el modo de pelear, ¿cómo no hay quien se atreva

a este campo a llegar?

9 Otros informantes dijeron: «Por el profeta Mahoma». 
Dime tan siquiera como vos llamáis.

Salga el ejército todo, si uno no vos atrevéis, enviarme aquí a Roldán, o al valeroso Oliveros, que deseo el conocerlos.

En aqueste suelo duro pienso de atar mi caballo.

Aquí quiero descansar a ver si vien d'alguno para conmigo pelear, que aunque vengan mil cristianos conmigo los he de llevar.

(Hay una silla y un árbol y se sienta Fierabrás en la silla)

REY CRISTIANO (CARLOMAGNO)

¿Quién es este hombre audaz

tan desatinado y ciego que nos está desafiando a cuantos hay en el reino?

4. ${ }^{\circ}$ CRISTIANO (RICARTE DE NORMANDÍA)

Ese osado caballero es hijo del almirante, agigantado en su cuerpo; el que sometió a Roma con notable atrevimiento, robó las santas reliquias que por tanto nos dolemos.

REY CRISTIANO (CARLOMAGNO)

(Llama a Roldán y le dice)

Sobrino, hoy es el día que a ti te toca el empeño de salir a la demanda de ese enemigo fiero. 


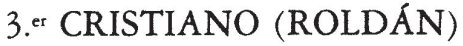

Ni yo ni mis compañeros,

no hemos de salir ninguno,

porque bien sabéis por cierto,

cuando en la escena pasada

de aquellos recios encuentros,

me dijisteis con firmeza:

«los ancianos caballeros

hoy han ganado la fama,

a éstos les toca primero

el salir a la demanda

contra ese enemigo fiero».

REY CRISTIANO (CARLOMAGNO)

Estás codenado a muerte

porque así has hecho el motivo.

Como rey que yo lo mando

y he de ser obedecido.

\section{2. ${ }^{\circ}$ CRISTIANO (OLIVEROS)}

Tráeme escudero las armas

y apareja mi caballo;

ten la tu arma en puño,

que yo la tengo en la mano.

4. ${ }^{\circ}$ CRISTIANO (GUARÍN)

Aquí tiene su caballo

bien comido y bien pensado, se ha comido un celemín

y no ha dejado ni un grano.

Aún no puede con la alforja, yo la llevaré en la mano.

Las armas están dispuestas

y el caballo aparejado, monte el señor Oliveros, que yo le daré la mano. 
2. ${ }^{\circ}$ CRISTIANO (OLIVEROS)

(Dirigiéndose a Carlomagno, le dice)

Muy poderoso señor, hoy llega este caballero pidiéndovos por merced le otorguéis su pedimento.

REY CRISTIANO (CARLOMAGNO)

Pide, que te lo concedo.

2. CRISTIANO (OLIVEROS)

Hoy vuestra licencia espero para ir a la campaña.

REY CRISTIANO (CARLOMAGNO)

Eso no te lo concedo, porque si bueno estuvieras no me darías recelo.

6. CRISTIANO (GALALÓN)

No es de nobles caballeros el negar esta demanda, sino afirmarse en ella.

REY CRISTIANO (CARLOMAGNO)

Tú tienes malas entrañas, pero al fin saldrá Oliveros, y mira que si fenece darás satisfacción de ello.

2. ${ }^{\circ}$ CRISTIANO (OLIVEROS)

Pagano, puedes alzarte, mira que tan sólo vengo a mantener en batalla todo cuanto estás diciendo, y que no serán tus obras conforme tienes tus fueros, 
que con la ayuda de Dios, dentro de muy poco tiempo, te he de llevar maniatado a mi señor y mi dueño.

2. ${ }^{\circ}$ MORO (FIERABRÁS)

Ve y dile a Carlomagno que tengo por menosprecio el emplear en ti mis armas; eres muy niño y pequeño. ¿Quién diablo te trajo acá a pelear con este guerrero? si es como poner ovejas contra un lobo carnicero.

2. ${ }^{\circ}$ CRISTIANO (OLIVEROS)

Si en levantarte tardas, como valiente te hiero.

2. ${ }^{\circ}$ MORO (FIERABRÁS)

Si he de pelear contigo dime tu nombre primero, tu calidad y nobleza, porque si no eres caballero, aunque te venza en batalla, poco galardón espero.

\section{2. ${ }^{\circ}$ CRISTIANO (OLIVEROS)}

Dime tu nombre primero y te diré el mío al instante.

2. ${ }^{\circ}$ MORO (FIERABRÁS)

Sabrás que por nombre llevo Fierabrás de Alejandría, el que a nadie tuvo miedo. 
2. CRISTIANO (OLIVEROS)

Pues yo me llamo Guarín, y soy caballero nuevo, la primera vez armado, y sólo por eso vengo

a ganar honor y fama con la victoria que espero.

2. MORO (FIERABRÁS)

Engañado estás en eso, porque si yo no tuviera piedad de ti, ya ha tiempo te hubiera dado muerte como a un débil cordero. Ve y dile a Carlomagno que me envíe aquí a Oliveros, o al valeroso Roldán, que deseo el conocerlos.

2. CRISTIANO (OLIVEROS)

Juzgo que me tienes miedo, según la pausa que gastas, y dejas pasar el tiempo.

Yo de ninguna manera me marcharé de este puesto sin que te hagas cristiano, o te lleve prisionero.

2. ${ }^{\circ}$ MORO (FIERABRÁS)

Pues no tienes remedio, apercíbete a las armas y siempre me hallarás dispuesto.

(Abora empiezan a pelear con espadas y luego continúa Fierabrás diciendo)

Paremos a descansar, porque ningún caballero tanto me duró delante, ni ha fatigado mi cuerpo. 
Ninguno en este mundo, sino tú; mas yo no creo que seas el que me dices, sino un genio del infierno. Así quiero que me aclares, palabras de juramento, por aquel Dios que veneras y aquella que está en el cielo, que me digas la verdad de cuanto yo te prometo.

2. ${ }^{\circ}$ CRISTIANO (OLIVEROS)

Pagano, ¿quién te enseñó con tal modo y acierto a conjurar los cristianos que no se niegan a ello? Sabrás, por cierto y verdad, que soy el conde Oliveros a quien tanto desafiabas y que no le tenías miedo.

2. MORO (FIERABRÁS)

(Le dice a Oliveros)

Me alegro de conoceros, y perdona los desaires que te hice de primero (danzan con los palos o triles, y luego continúa Fierabrás)

[2." parte] Has de saber, noble conde, que he estimado el conoceros. Ahora, si tú quisieras, hiciéramos un propuesto: de que olvidaras tu ley y te vendrías a mi reino, te casarías con mi hermana, dama de virtud y aprecio, Floripes, bella princesa, y mis padres de su reino 
te darán parte de tierras

y también yo haría lo mismo,

y luego, los dos juntos, entraríamos en ese imperio

a destronar a Carlomagno.

Habiendo siempre el concepto

que todo lo conquistado

será para ti, y luego

te colocarán por rey

de ese poderoso reino.

\section{CRISTIANO (OLIVEROS)}

No me platiques en eso;

¿cómo quieres que yo olvide

a un Dios tan sabio y tan bueno, que con todo su gran poder creó la tierra y el cielo, aves, plantas y animales, todo cuanto hay terreno, para adorar a tus dioses que son falsos y embusteros, inventados por los hombres? Mejor será y más perfecto que tú te vuelvas cristiano, y serás mi compañero para defender la fe de Cristo Redentor nuestro.

\section{( $Y$ continúa Oliveros diciendo}

esta oración)

Oh, Dios, ten misericordia, oh, cielos santos ¿qué es esto? oh, pagano tan osado, que con tanto atrevimiento... por aquel Dios que venero y aquella que está en el cielo, 
no verás eso, pagano, sino castigo soberbio ${ }^{10}$

$2 .^{\circ}$ MORO (FIERABRÁS)

¿Qué oración es la que has hecho?

¿Con ella te has de sanar?

Mas por merced te ofrezco, que vengas a mis barriles, tomarás un sorbo de ellos y al instante estarás sano.

(Tenian allí unos barriles de madera con el bálsamo de las reliquias)

\section{CRISTIANO (OLIVEROS)}

No quisiera yo nada tuyo, si no lo gano primero.

4. ${ }^{\circ}$ CRISTIANO (GUARÍN)

(Le dice a Carlomagno)

Ruega a Dios por Oliveros, que está en grande peligro.

\section{REY CRISTIANO (CARLOMAGNO)}

Dulce Jesús de mi vida, amantísimo Cordero, consuelo del afligido, mirad por mi caballero.

Estando en esta plegaria oyó una voz del cielo que le dice: Carlomagno, no tengas temor ni miedo porque, aunque sea costoso, será tuyo el vencimiento.

10 En el manuscrito está la siguiente oración: «Sagrada Celestial Princesa/ María Madre del Verbo/ a vuestras divinas plantas/ hoy humildemente llego,/ pidiéndote, Madre mía,/ me des luz, favor y acierto,/ para poder convertir/ a este turco soberbio», que es la misma del texto base. 
2. MORO (FIERABRÁS)

(Cuando ve que Oliveros tira los barriles, dice)

Mala acción es la que has hecho, presto te han de hacer falta.

( $Y$ alzando el brazo soberbio, Fierabrás mata el caballo con la espada)

\section{CRISTIANO (OLIVEROS)}

No es de nobles caballeros

dar muerte a los caballos

estando en campaña puestos.

2. MORO (FIERABRÁS)

Yo de eso culpa no tengo, pero yo te daré el mío, aunque de verdad lo siento.

\section{2. ${ }^{\circ}$ CRISTIANO (OLIVEROS)}

No quiero yo tu caballo, sino que te apees luego, y el que venza la batalla, ese quedará por dueño.

2..$^{\text {MORO (FIERABRÁS) }}$

Contémplate prisionero

o te quitaré la vida.

(Fierabrás quita la espada

a Oliveros)

\section{2. ${ }^{\circ}$ CRISTIANO (OLIVEROS)}

Obra como tú quisieras, que si no me llevas muerto no es posible el entregarme. 
(Oliveros coge la espada, y dice)

Turco, ya tengo espada, ahora aquí nos veremos.

2. MORO (FIERABRÁS)

Mucho en el alma lo siento, ven y tomarás la tuya, y dame la mía en premio.

2. ${ }^{\circ}$ CRISTIANO (OLIVEROS)

Primero quiero templarla por ver si es fuerte el acero, y si no es como la mía luego después trocaremos.

2. ${ }^{\text {MORO (FIERABRÁS) }}$

¡Oh valeroso cristiano!, si un segundo es más tu esfuerzo, no me acabes de matar, que desde ahora confieso que es tu Dios muy poderoso, infinito y verdadero.

Llévame preso, cristiano, donde están tus compañeros, y dame el santo Bautismo que por instantes deseo.

2. CRISTIANO (OLIVEROS)

Levántate, noble amigo, que ahora curarte quiero las dos heridas mortales, que Dios te dará el remedio.

2. ${ }^{\circ}$ MORO (FIERABRÁS)

No dilates mucho tiempo, que tengo doce mil hombres en ese monte encubiertos. 


\section{2. ${ }^{\circ}$ CRISTIANO (OLIVEROS)}

Mucho en el alma lo siento

el no poderte llevar

donde están mis compañeros,

que viene toda tu gente

y nos corre grande riesgo.

[3." parte] (Vienen los moros y les encierran a los

cristianos en la torre, que tienen becha con

maderos y sábanas. Abora danzan con los

palos)

2. CRISTIANO (OLIVEROS)

¡Ay, desdichado de mí,

que de esta suerte me veo!,

hombre mal afortunado,

si permitieran los cielos

que yo saliera de aquí,

desde luego les prometo

a los que niegan la fe

castigarlos con mi acero.

DAMA (FLORIPES)

Carcelero Brutamonte,

dime qué hombres son esos.

3. ${ }^{\text {er }}$ MORO

Estos cinco caballeros

son pares de Carlomagno

grandes contrarios nuestros.

DAMA (FLORIPES)

Yo pienso bajar a verlos.

3.er MORO

Por dos cosas no conviene:

porque es el lugar hediondo, abominable en extremo, además que vuestro padre 
me los entregó diciendo, bajo pena de la vida, que nadie hablase con ellos, y el fiarse de mujeres suele traer malos riesgos.

DAMA (FLORIPES)

Dame, carcelero, las llaves que tienes de ese castillo, que quiero ir a ver los presos que tienes ahí cautivos.

3.er MORO

Las llaves no te las doy, ni aunque me quemaran vivo, porque me encargó tu padre que de nadie fueran vistos, y ahora estoy escarmentado y de mujeres no me fío.

DAMA (FLORIPES)

Quítate de mi presencia, que eres ignorante y necio, tú también irás conmigo y escucharás lo que hablemos.

(Floripes mata al carcelero con una espada que llevaba bajo el mandil)

2. CRISTIANO (OLIVEROS)

(Al ver a Floripes dice)

Qué gran dicha tenemos los pobres encarcelados, pues nos sirve de consuelo tu inesperada visita.

DAMA (FLORIPES)

¡Quién sabe si mi venida

es para daros tormento! 
2. CRISTIANO (OLIVEROS)

En tan generoso pecho

no pueden caber maldades, sino buenos sentimientos.

¡Bendito el que te crió

tan bellísimo portento!

Si yo mereciera, señora,

el poder lograr mi intento, que te volvieras cristiana, yo te llevaría a mi reino.

Recibieras el bautismo que es una joya sin precio, estuvieras con tu hermano con gran placer y contento. Y si lograra la dicha, yo, y mis cuatro compañeros, de hallarnos bien armados y con buenos alimentos, los cinco somos bastantes para conquistar tu reino. $\mathrm{Y}$ desterrar de esa tierra el culto falso y protervo.

DAMA (FLORIPES)

¿Quién eres tú, el que hablas tan determinado y resuelto, metido entre cadenas, amenazando a los sueltos? Dime pues cómo se llama tu linaje y descendencia ${ }^{11}$

\section{4. ${ }^{\circ}$ CRISTIANO (OGIER DE DINAMARCA)}

Señora, es tanto el deseo

y voluntad de serviros

de mi amigo, que entiendo

11 Una informante, Celia, recordaba así otra estrofa, que ella dijo cuando actuó en la obra como Floripes: "¿Qué hablas tú, caballero!/ amenazando a los sueltos/ ¿si aún estás entre cadenas?/ dime, pues, cómo se llama tu linaje y descendencia». 
que la muy grande pasión

le hace hablar sin concierto.

DAMA (FLORIPES)

Bien sabes defender a tu compañero.

Os pregunto por vuestros nombres.

$2 .{ }^{\circ}$ CRISTIANO (OLIVEROS)

Yo soy el Conde Oliveros, hijo del Duque Reiner, humilde servidor vuestro.

DAMA (FLORIPES)

¿Cómo venciste a mi hermano, siendo tan buen caballero?

2. CRISTIANO (OLIVEROS)

Con la ayuda de Dios, y la reina de los Cielos. Ésta es la causa, señora, de hallarme prisionero, y lo tengo a gran dicha por haber visto a tu cielo.

DAMA (FLORIPES)

Me habéis de dar la palabra bajo fe de juramento, de ampararme y defenderme y de guardarme el secreto.

Sobre lo que soy venida es por ver si un caballero, que llaman Guy de Borgoña, está en tu acompañamiento, que hará tres años cabales que lo vi en los torneos y en las justas con mi primo hacer valerosos hechos. $\mathrm{Y}$ desde entonces quedé 
que ni duermo ni sosiego

en pensar en su persona.

Y si lograra mi intento

que quisiera ser mi esposo,

renunciaría a mi reino,

y me volvería cristiana

por tener tan dulce dueño.

2. CRISTIANO (OLIVEROS)

Señora, ese noble caballero

se quedó con Carlomagno.

Mas no os dé cuidado d'eso,

porque es muy amigo mío

y mi más cercano deudo,

y hará cuanto yo le mande,

y cumplirá vuestros deseos.

DAMA (FLORIPES)

Quedaos en paz, caballeros, que antes que amanezca el día os sacaré de este encierro.

(Saca a los cristianos de la torre, les da vestidos nuevos, $y$ dice al Conde Oliveros)

¿Muy bien os cae el vestido?

2. CRISTIANO (OLIVEROS)

El hábito no hace monje, lo mejor fuere, y más cierto, el hallarme bien armado para poder defendernos.

(Abora llega una embajada de los cristianos)

3. er MORO

Decidme cómo os llamáis y vuestros nombres primero. 
3.er CRISTIANO (ROLDÁN)

Somos siete caballeros, vasallos de Carlomagno, que pasamos con un pliego al almirante Balán.

4..$^{\circ}$ MORO

No me es posible el creeros;

y así, entrégame las armas,

y ríndete prisionero,

que te prometo la vida.

3.er CRISTIANO (ROLDÁN)

¿Cómo he de entregar mis armas?

Dirían mis compañeros

que no soy para llevarlas

al africano soberbio ${ }^{12}$

(Se vuelve Roldán a los suyos y les dice)

Señores, ¿qué dirán los caballeros?,

¿que nos volvemos atrás

temerosos de los riesgos?

[4." parte] 4. MORO

Señor, siete caballeros

en la mitad del camino

nos salieron al encuentro,

y fueron tan valerosos

que en muy breves momentos

a catorce dieron muerte, mas yo me escapé huyendo.

Esta es la verdad por cierto,

que si habéis de castigarlos

miray que no sean dueños

de poder usar de armas, que si las toman, por cierto,

12 En el texto base: «que no soy para llevarlas./ $\mathrm{Y}$ el africano soberbio/ puso la mano en su lanza». 
que no podrán sujetarlos

todo el poder de tu reino.

5. MORO

Muy poderoso Señor, nuestros dioses son muy buenos pues han traído a la corte a los que tan mal te han hecho. Antes que amanezca el día os los tengo que dar presos.

(Presentan a los cinco embajadores cristianos ante el rey moro)

REY MORO (BALÁN)

Decirme cómo os llamáis

y me daréis vuestro nombre.

3.r CRISTIANO (ROLDÁN)

Sabrás que yo soy Roldán, uno de los caballeros vasallos de Carlomagno que venimos con un pliego, a presentarlo a esta corte. Pero dos enviados vuestros en la mitad del camino poco corteses han sido: intentaron desarmarnos, y dentro de poco tiempo dimos muerte a los catorce; el otro se escapó huyendo. Aquí traigo las cabezas por si no queréis creerlo.

REY MORO (BALÁN)

(Dirigiéndose a Roldán, dice)

¿Qué diablo te envió acá?, ¿quién te quitará tu reino? 
3.er CRISTIANO (ROLDÁN)

Si no te haces cristiano

y entregas los caballeros

y las Sagradas Reliquias,

porque he hecho juramento

de quitarte la corona

y destruirte tu imperio.

REY MORO (BALÁN)

No, llevarás la respuesta:

que dentro de poco tiempo,

han de ser descuartizados

y por los caminos puestos.

REY MORO (BALÁN)

¿Quién es este caballero?

4." CRISTIANO

Soy Ricarte de Normandía.

REY MORO (BALÁN)

Me alegro de conoceros, que ahora me pagarás

los agravios que me has hecho.

(Y mirando bacia Guy de Borgoña, dice:)

¿Quién eres tú, muy discreto?

5." CRISTIANO (GUY DE BORGOÑA)

Yo soy el Guy de Borgoña.

REY MORO (BALÁN)

También tuve gran deseo

de pillarte en mi poder. 


\section{5. ${ }^{\circ}$ CRISTIANO (GUY DE BORGOÑA)}

Si tuvieras buena sangre, y fueras buen caballero

y te preciaras de noble, no hicieras estos propuestos de querer darnos la muerte, oprimidos y sujetos, si no darnos nuestras armas, prevenir todo tu reino, y si acaso nos matasen, caro te saldría el duelo.

DAMA (FLORIPES)

(Le dice a Oliveros)

Ya ha llegado la ocasión

de que mostréis vuestro esfuerzo ${ }^{13}$.

Que a vos y a los compañeros

que he hecho en esta torre

que están siete caballeros, entre ellos Guy de Borgoña, dentro del palacio puestos, en presencia de mi padre que encolerizado y ciego, los ha sentenciado a muerte, y también a vos con ellos.

Yo pienso ir a palacio y ver si puedo traerlos, y si acaso no pudiese, lo que yo os suplico y ruego, es que seais diligentes en el salir al empeño.

(Floripes va hacia su padre, el rey moro, $y$ le pregunta)

¿Quién son esos caballeros?

${ }^{13}$ En el texto base sigue así: «Y me paguéis las finezas/ que a vos y los compañeros/ he hecho en aquesta torre...». 
REY MORO (BALÁN)

Vasallos de Carlomagno, los que tengo a gran deseo, antes que concluya el día, darles castigo muy fiero.

DAMA (FLORIPES)

No conviene que tan presto ejecutéis el castigo, sin darle vado al tiempo. Permitidme que los lleve a donde los otros tengo.

5. MORO

¡Oh! muy poderoso Señor, ¿no habéis leído ejemplos en las historias pasadas, y podéis saber, por cierto, que el fiarse de mujeres suele traer grandes riesgos?

DAMA (FLORIPES)

Villano, lo pagarás.

Hoy por mi fe te prometo que te has de acordar de mí, y yo presos me los llevo ${ }^{14}$

2. ${ }^{\circ}$ CRISTIANO (OLIVEROS)

(Le dice a Guy de Borgoña)

Sabed, noble amigo, que a vos sólo os debemos el que nos halléis con vida, y el vernos libres del riesgo en que os habéis metido. Daréis agradecimiento a la princesa Floripes,

14 En el texto base: «y llevándose los presos/ donde los otros estaban...». 
que es nuestro amparo y remedio.

Está tan apasionada

de vos, señor, y con esto

quiere volverse cristiana

para que seáis su dueño,

y yo le he dado palabra;

con que es preciso el hacerlo.

5. CRISTIANO (GUY DE BORGOÑA)

Si no es más que eso, desde el instante que vi la hermosura de su cielo quedé rendido en sus plantas y el corazón tan sujeto, que si mil vidas tuviera todas las pusiera en riesgo, por defender su persona y sacarla de ese reino.

DAMA (FLORIPES)

(Saca el anillo y se lo entrega)

Sea esta prenda testigo ahora y en todo tiempo.

6. MORO

Entonces llegó a palacio un hermoso caballero, sobrino del almirante y preguntando por ellos: estos caballeros ¿dónde están?

REY MORO (BALÁN)

Entre cadenas y hierros los tiene mi hija Floripes. Si queréis hablar con ellos bajaos presto a la torre, y ejecútelo al momento ${ }^{15}$

15 En el texto base: «y lo ejecutó al momento». 
$6 .^{\circ} \mathrm{MORO}$

No quisiera haber venido, por no hallarme en tanto riesgo.

DAMA (FLORIPES)

(Ve matar a un moro, su primo, $y$ dice)

No ha sido el golpe de viejo, sino de joven bizarro.

6. CRISTIANO (DUQUE NAIMES)

Pues otros verás mayores,

si Dios me da buen acierto.

DAMA (FLORIPES)

Señores, os dejo un momento, que mi padre está aguardando, pues me tengo por muy cierto, que no ha de comer sin mí.

Dentro de un momento vuelvo ${ }^{16}$

REY MORO (BALÁN)

(Le pregunta a su bija, diciendo:)

Dime dónde está el sobrino, pues llega y dile que venga, que se va pasando el tiempo.

DAMA (FLORIPES)

Allá abajo quedó hablando con los otros caballeros.

(Ahora va Floripes a la torre, donde están los cristianos)

16 Continúa el manuscrito, siguiendo el texto base: «Y a su padre el pretexto/ que ella comer no quería,/ que se halla mal dispuesto/ su cuerpo por la cuestión/ de aquel falso caballero». 
DAMA (FLORIPES)

Os digo, mis caballeros, si os falta algún pertrecho, porque ha llegado la hora de que salgáis de ese encierro.

[5." parte] 3.er CRISTIANO (ROLDÁN)

Uno de los caballeros es menester que se vaya a dar cuenta a Carlomagno, que nos envíe refuerzo, porque si no pereceremos.

4. CRISTIANO (RICARTE DE NORMANDÍA)

El ir solo bien me atrevo, que sé muy bien el camino, tan sólo a la puente le temo, pero me daré trazas a ver si pasarla puedo.

6. ${ }^{\circ}$ MORO

Aquel que vea a Carlomagno, prenderle luego al momento.

5. MORO

Pues yo sólo he de ir y lo daré vivo o muerto.

4. ${ }^{\circ}$ MORO

Di, villano, ¿dónde vas?, ¡ríndete aquí prisionero o te quitaré la vida dentro de muy breve tiempo!

4. ${ }^{\circ}$ CRISTIANO (RICARTE DE NORMANDÍA)

A bien que solos estamos, ahora aquí nos veremos. 
REY CRISTIANOO (CARLOMAGNO)

Dime tú, noble vasallo, ¿a dónde están mis varones?

4. CRISTIANO (RICARTE DE NORMANDIA)

Quedan dentro de una torre, muy escasos de alimentos, y la Princesa Floripes también quedaba con ellos.

Dadme licencia, señor, con cincuenta caballeros que cubriendo nuestras capas, como que vamos al reino a llevar mercaderías, conseguir, así podremos, que el gigante ceda el paso. Y después que estemos dentro, meter mano a nuestras armas, y soltar las capas diestros.

(Dan el paso los cristianos por detrás de los moros)

$6 .^{\circ}$ MORO

¡Alto!, quién sois caballeros.

Decidme a ver qué buscáis, que si no me lo decís, por este puente no pasáis.

4. CRISTIANO (RICARTE DE NORMANDIA)

Somos unos mercaderes

que pasamos por el reino

del almirante Balán

y el tributo le traemos, que se paga en este puente. 
5. MORO

Cada uno un marco de oro

me habéis de dar,

y con esto pasaréis por este puente

sin que os venga ningún riesgo ${ }^{17}$

4. ${ }^{\circ}$ CRISTIANO (RICARTE DE NORMANDÍ)

Abre, te enterarás de ello.

Mira bien aqueste pliego

y verás lo que traemos.

6. MORO

Venga acá ese Carlomagno

y todos sus compañeros, que tienen el paso franco;

vengan, aquí los espero.

(Luchan con espadas)

[6." parte] 3.er MORO

Dime, pues, noble señor, ¿qué hacéis?, que eso no es bueno, pedid perdón de la injuria

a nuestros dioses, que es cierto

los habremos menester

por ver si acaso podemos

apresar a Carlomagno

dándole castigo fiero.

4. ${ }^{\circ}$ MORO

Pues yo te perdono, y así

prevén tu gente al momento,

que has de vencer en batalla,

y de todo serás dueño.

17 Recuedan aquí también los informantes esta estrofa que dijeron: «Me daréis cien doncellas,/ también cincuenta perros,/ once gatos todos negros,/ para con ellos cazar./ Sin esto no pasáis el puente,/ aunque sepáis bien pelear.» 
2. ${ }^{\circ}$ MORO (FIERABRÁS)

Muy poderoso señor,

sólo una merced te ruego, que publiques en tu real, de que cualquier caballero que se encuentre con mi padre, no le dé muerte, que quiero ver si puedo convertirlo y que reciba el bautismo.

REY CRISTIANO (CARLOMAGNO)

Te concedo, noble amigo, todo cuanto estás diciendo, que le ruegues a tu padre que se venga a nuestro reino.

6. CRISTIANO (GALALÓN)

(Embajada al rey moro)

La embajada que te traigo: si quieres hacerte cristiano y entregar los caballeros con las Sagradas Reliquias, que se quedará en su reino, y se firmarán las paces, bajo el formal convenio.

REY MORO (BALÁN)

No serás buen caballero cuando tu señor te envía con un mensaje tan necio.

6." CRISTIANO (GALALÓN)

Nosotros nunca podemos negarnos a la obediencia $y$ te aseguro, por cierto, si no enmiendas tus errores, y te empeñas en ser terco, tendrás por qué arrepentirte y no tendrás remedio. 
4..$^{\circ}$ ORO

Salga acá ese Carlomagno

y veremos los dos viejos

cuál se lleva la victoria,

y cuál quedará por dueño.

REY MORO (BALÁN)

(Habla con su bijo Fierabrás)

¿Sois acaso Fierabrás?, porque yo a ti te conozco

en los valerosos hechos.

2. MORO (FIERABRÁS)

(A su padre)

¡Oh!, padre del corazón, yo os suplico y ruego, que os volváis cristiano y creáis en Dios del cielo, en la Virgen celestial

y en la reina de los cielos.

REY MORO (BALÁN)

¡Oh!, nunca hubieras nacido

para no darme tormento, tú vives muy engañado, y en ti gran venganza espero.

2. ${ }^{\circ}$ MORO (FIERABRÁS)

Dulce padre de mi vida, deje esos ídolos fieros, recibe el Santo Bautismo y tendrás parte en el cielo.

REY MORO (BALÁN)

En balde es cansarte, necio, que mejor quiero morir que no olvidar mis preceptos 
de mi profeta Mahoma, que son muy santos y buenos.

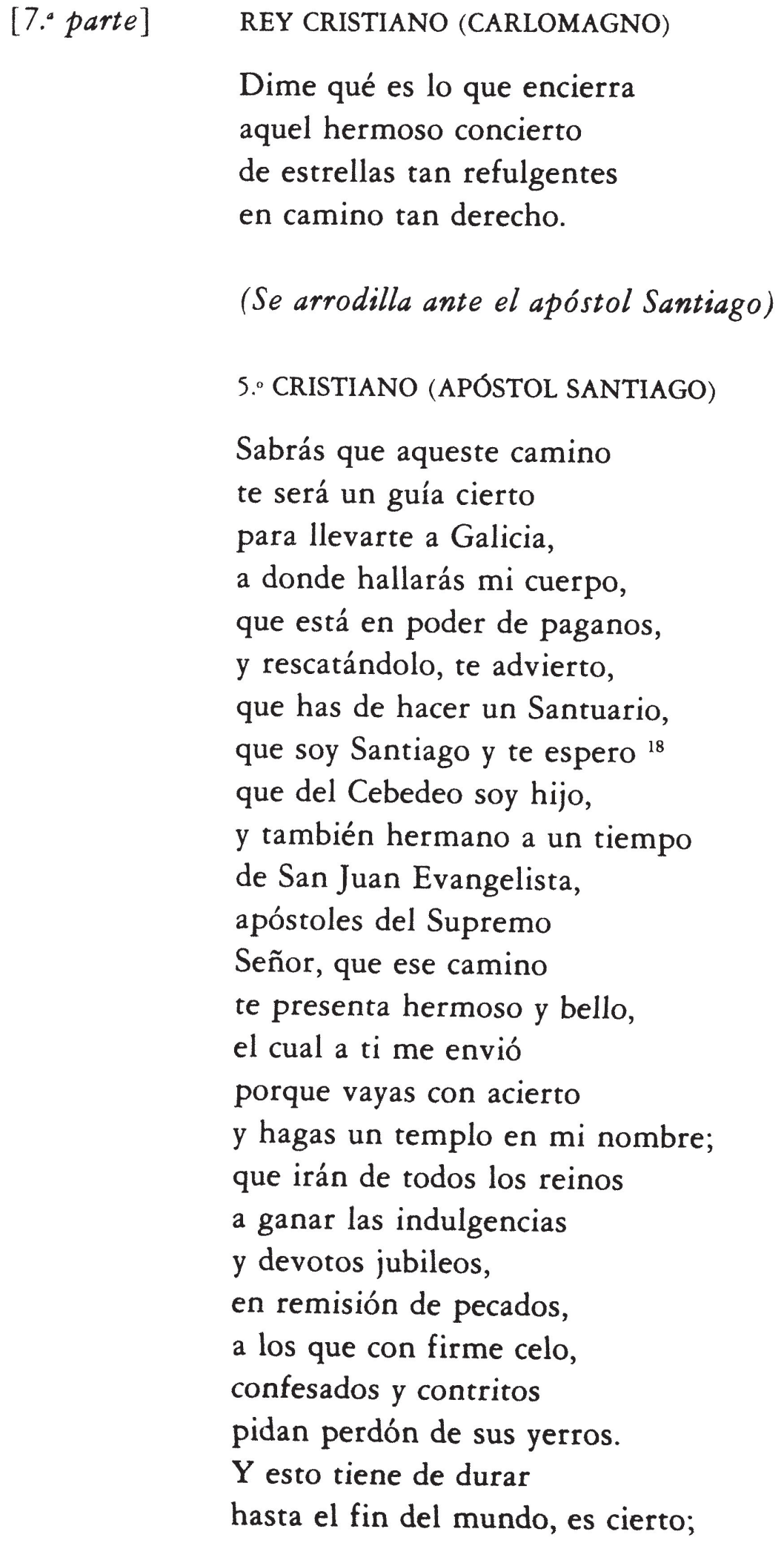

18 En el texto: «te expreso». 
que el Señor me ha concedido

todos estos privilegios 19

(Danzan con los palos)

REY MORO (BALÁN)

Ven acá, tú, Ferraguz, agigantado y soberbio, el cual tiene de alto sobre diez palmos y medio, fuerza de cuarenta hombres y muy fornido de cuerpo, te entrego treinta mil hombres para que salgas con ellos a dar guerra a Carlomagno $y$ te partas al momento ${ }^{20}$

4. ${ }^{\circ}$ MORO

Los he de traer atados y he de acabar con ellos; le diré a Carlomagno que se haga un convenio, brazo a brazo, o cuerpo a cuerpo.

REY CRISTIANO (CARLOMAGNO)

Vos, mi noble caballero, os hemos escogido

para ir por mensajero, y digáis a esos virreyes que de mi parte les ruego que se conviertan cristianos, siguiendo a Dios verdadero. El cual creó cielo y tierra, a nuestros padres primeros, padeció muerte y pasión

19 Recuerdan otra versión para el final: «Esto es cierto;/ que el Señor me ha revelado/ todos estos privilegios».

20 Este párrafo está tachado en el manuscrito, así como el otro que sigue, en boca del $4 .^{\circ}$ moro. 
por librarnos del infierno,

y que dejen a sus dioses,

que son falsos y embusteros.

[8.a y ültima

6. CRISTIANO (GALALÓN)

parte]

Aquí os traigo una embajada

de parte de los cristianos,

si me dais algún dinero

os lo entrego en la mano.

REY MORO (BALÁN)

En el hablar conozco

que eres venal caballero,

les haces esa traición

por codicia del dinero.

Les dices que en Roncesvalles

esperamos los caballeros.

(Contestación de la embajada de

Galalón al rey cristiano)

6." CRISTIANO (GALALÓN)

P'al campo de Roncesvalles

salgan los caballeros,

bien equipados y armados.

La flor de los caballeros

que quieren ser cristianos,

por ahora y por momentos.

REY CRISTIANO (CARLOMAGNO)

Que Dios te dé el galardón, según has hecho el encargo.

3." CRISTIANO (ROLDÁN)

(Aqui coge el tercer cristiano al cuarto

moro por el pescuezo y le dice) 
Muéstrame luego al virrey,

y si no lo haces así,

te he de cortar el pescuezo ${ }^{21}$

3.er MORO

Mira muy atentamente

por todo este campo extenso,

el de la visera verde,

caballo bayo, es el mismo,

y dio a vuestro embajador

muchas joyas y dineros,

sólo para que os enviase

a lo mismo que estás viendo.

3.r CRISTIANO (ROLDÁN)

(Se tiende Roldán en la parte de

los cristianos y dice:)

Ten, Señor, misericordia

de aqueste tu caballero, que por defender la fe se ha visto en tantos aprietos.

Hoy doy la vida por ti, solo, en este monte espeso.

Recibe, Señor, mi alma, que goce de ti en el cielo de tu eterno descanso, por quien tanto padezco.

(Luego coge su espada y da con ella en un palo que alli se pone y dice Roldán)

¡Oh espada de gran valor, la mejor que hombres han hecho! ¡Cuánto tiempo me has servido y a cuantos turcos has muerto! $\mathrm{Y}$ con tus cortantes filos has partido tantos yelmos,

21 En el texto base: «Muéstrame luego al momento/ al virrey Marsilio, o bien/ te he de cortar el pescuezo». 
no quisiera te gozara

ninguno, y por eso quiero

en esta piedra quebrarte ${ }^{22}$

(Aqui va un cristiano donde está Roldán

y éste le dice:)

Soy Roldán, tu compañero, el que dio muerte al gigante

tan feroz y tan soberbio, y que en las recias batallas cuidó de sus compañeros. Oyeme de confesión porque yo me estoy muriendo.

REY CRISTIANO (CARLOMAGNO)

(Va donde está Roldán y le dice:)

Sobrino del alma mía, cuánto en el alma lo siento, después de tantas batallas verte en este sitio muerto. ¿Por qué te vas y me dejas? ¡Ay! desconsolado viejo, espada de mi justicia, tu arrogancia y esfuerzo eran mi firme sostén contra los turcos soberbios.

Los mártires te reciban y tengan por compañero. Goza de la eterna gloria, colocado allá en el cielo, y tu apreciada memoria pues nos sirva de consuelo.

Concha Casado lobato

C.S.I.C., Madrid

22 Recuerdan los informantes este otro verso que también decía Roldán: «Ay, ay, ay, que me mataron./ Valeime Virgen María/ en esta última hora./ Me muero sin confesión/ que otro remedio no había./ ¡Ay la mi madre querida!/ Pa qué criaréis los hijos/ para quedar por estos matorrales/ tendidos como las hojas de los árboles». 

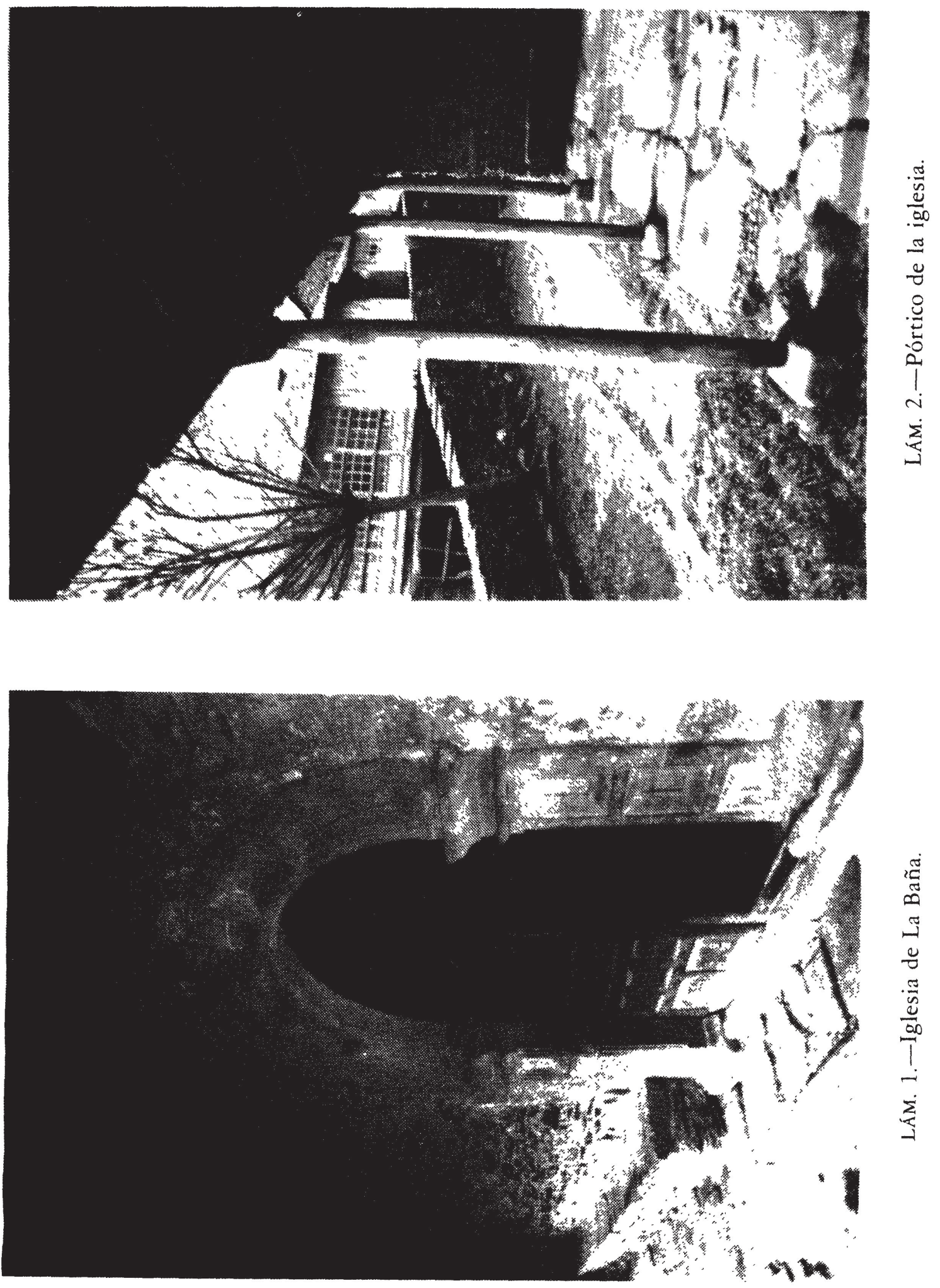

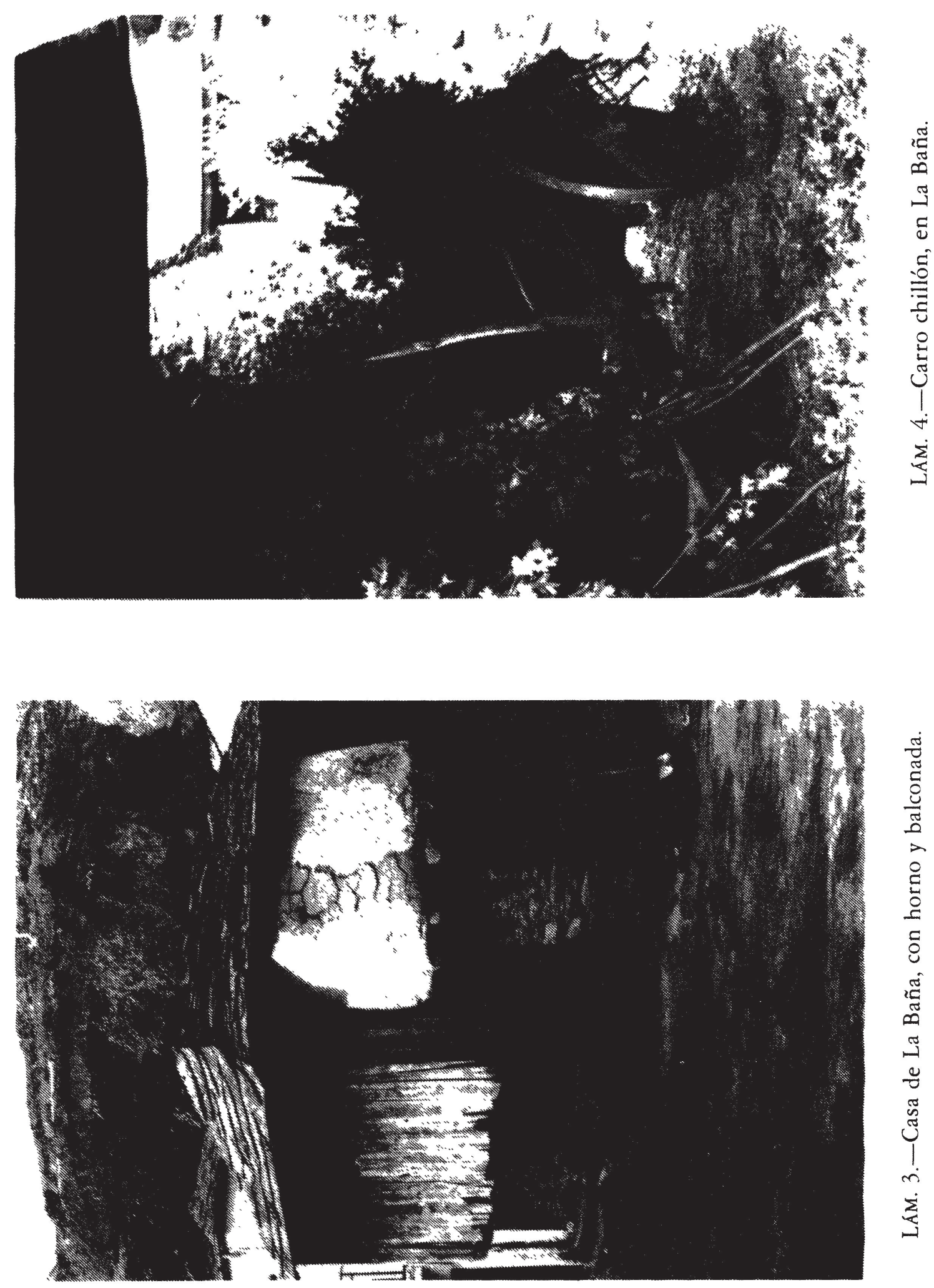

రే 